\title{
THE MAIN CHALLENGES OF DIGITAL COMMERCE IN THE CONDITIONS OF "COVID-19"
}

\section{TAMAR MAKASARASHVILI}

Academic Doctor of Economics, Professor

Gori State Teaching University, Georgia

tmakasarashvili@gmail.com

\section{GIULI GIGUASHVILI}

Academic Doctor of Economics, Professor

Gori State Teaching University, Georgia

giuligiguashvili@gmail.com

Abstract. The Coronavirus pandemic has posed new challenges to Georgia's economy and business. The use of online technologies in the field of business has gained special urgency. To reduce the negative consequences of the crisis, it became necessary to massively switch to online sales, the introduction of new and modern methods of business processes, which will allow customers to virtually, without leaving home, make sales, transfers, and payments. The companies, which find their niche in the virtual world on time, have more chances of success. Speed, convenience, flexibility, and accessibility are the main advantages of digital commerce and are especially important in pandemic conditions.

The main goal of the research is to define the role of digital commerce in the conditions of COVID-19, to identify new opportunities to increase the efficiency of existing platforms, to introduce e-commerce models in the Georgian business space, to increase the efficiency of digital commerce platforms and to solve related problems.

\section{KEYWORDS: E-COMMERCE, ONLINE SALES, B2B PLATFORM.}

For citation: Makasarashvili, T., Giguashvili, G., (2021). The Main Challenges of Digital Commerce in the Conditions of "Covid-19". Globalization and Business, №11, 139-142. https://doi.org/10.35945/gb.2021.11.020

\section{INTRODUCTION}

The Coronavirus pandemic has posed new challenges to Georgia's economy and business. The use of online technologies in the field of business has gained special urgency. To reduce the negative consequences of the crisis, it became necessary to massively switch to online sales, the introduction of new and modern methods of business processes, which will allow customers to virtually, without leaving home, make sales, transfers, and payments. Companies that find their niche in the virtual world on time have a better chance of success. Speed, convenience, flexibility, and accessibility are key advantages of digital commerce and are especially important in a pandemic. The use of digital platforms against the backdrop of the global pandemic has reached a peak. The motto of online services has become vital - take on a new business space, offer your products to more customers and increase sales!

\section{AIM AND OBJECTIVES OF THE RESEARCH}

The main goal of the research is to determine the role of digital commerce in the conditions of COVID-19, to iden- tify new opportunities to increase the efficiency of existing platforms, to introduce e-commerce models in the Georgian business space, to increase the efficiency of digital commerce platforms in virtual reality.

\section{RESEARCH OBJECT}

E-commerce refers to a business that electronically manages both product and/or service collections, as well as payments. These are actions aimed at buying or selling a product through online services or the Internet (Kanchaveli, 2019). Commerce can be considered as a service that allows services and products to be made available to customers through social media and used as payment means Visa and MasterCard plastic cards, increase sales volume, expand sales area worldwide, make the offered services and products more accessible to customers.

\section{MAIN PART}

Given today's reality, e-commerce is a major, vital factor for companies. During the quarantine period, home users tried to access various services or products through social 
media. With minimal costs, it is possible to offer the most comfortable service to the customer:

- Information services;

- Online stores;

- Online Education;

- Web services;

- Auctions;

- Utilities;

- Advertising services;

- Courier services;

- Services of state organizations.

The Coronavirus pandemic has taken B2B companies to the brink of popularity, with e-commerce services becoming particularly in demand. According to a 2020 study by McKinsey \& Company, more than $75 \%$ of B2B buyers and sellers choose to access social media online. Only $20 \%$ of B2B buyers think they want to return to traditional personal sales. On a positive note, the fact that, according to a study by McKinsey \& Company, B2B shoppers are willing to spend more when shopping online (Arno Ham, 2020). As the world-renowned business data platform Statista predicts, B2B sales will reach \$ 1.2 trillion by 2021 (https://ecommerceguide.com/guides/ b2b-ecommerce-market-trends-and-best-practices/).

$\mathrm{ACl}$ Worldwide.com in April 2020 published a study on how the share of digital commerce has changed compared to March 2019. It was found that the volume of transactions in the retail sector increased by an average of $74 \%$ ( $\mathrm{ACl}$ Worldwide, 2020). Leading among the popular items purchased through the internet are: small items, gardening items, laptops, and TVs.

According to the research, the data were distributed as follows:

- Primary goods and furniture $+97 \%$;

- Horticultural items + $163 \%$;

- Electrical engineering $+26.6 \%$.

Reduced volume in the same period:

- Tickets - 60\%;

- Travel - 44\%.

While global retail sales will be declined by $5.7 \%$ in 2020 due to the coronavirus pandemic, Amazon's global sales increased by $26 \%$ in Q1 and by $40 \%$ in Q2, while e-commerce spending in the US increased from $11.8 \%$ to $16.1 \%$ in Q2 in the first quarter (Olivia De Beukelaer, 2021).

Visual Capitalist (https://www.visualcapitalist.com/) publishes top 10 fast-growing infographics based on sources such as Amazon, Business Insider, Euro News, CNBC. At the initial stage, the citizens were mainly creating stocks of products. Later, as shown in the infographic, compared to March 2019, in March 2020, no matter how strange it may seem, after disposable gloves and hygiene items, the second place is occupied by household appliances, more specifically - bread baking. A large part of the population decided to bake bread themselves (Katie Jones, 2020). It should be noted that the increased demand for bread bakeries was also observed in the Georgian market. Online grocery stores have acquired a special load. Given that COVID-19 global pandemic, shop visits can be life-threatening for individuals or families, as well as the nation, we cannot disagree with most researchers that online grocery stores are the best solution to all problems and e-commerce has no alternative to pandemics (Khan, 2020).

At the beginning of 2020 , an e-commerce association was established in Georgia. The mission of the organization is to promote and encourage the development of this direction in the country, and the main goal is to obtain and share information or knowledge among local, regional and international market players. The share of e-commerce in retail turnover in Georgia is less than $2 \%$, the association will help to realize the existing potential in this direction and the development of companies playing in the domestic market of the country. The motto of the organization: Turn circumstance into an opportunity (https://www.marketer.ge/georgian-el-commerce-association/).

E-commerce relies on technologies such as e-Funds Transfer, Supply Chain Management, Internet Marketing, Online Transfer Process, Electronic Data Interchange (EDI), Inventory Management Systems, and Automated Data Collection Systems. When we talk about the online sector, it is important to understand the volatile and ever-changing circumstances that exist. That is why it is necessary to constantly meet new needs. In the modern world, there are several types of e-commerce products to choose from:

- An online store with its product: This is the starting point for an e-commerce business model. Here is the same approach as in a traditional store, however, with one difference - you sell products online. (Via the Internet);

- Online store with someone else's product: In this case, the seller is a third party who cooperates with the product supplier and sells his products to someone else in exchange for a commission;

- Related E-Commerce Business (Affiliate E-Commerce): When an e-commerce representative does not trade products directly but aims to bring the buyer to another business product and make a profit from the products sold in the process. Similar business models are quite common in the modern world. There are well-known blogs that spread information about a particular product/service, and when a user is redirected from that source and purchases that product, the system remembers the source and charges a fee;

- Membership-based: More and more businesses are trying to involve the customer in the process of multiple and long-term relationships instead of selling the product to him once and thus end the relationship. To achieve this goal, e-commerce platforms offer membership offers in exchange for certain packages (receiving certain benefits once a week, month, once a year), which, accordingly, requires payment periodically;

- Catalog websites (marketplace): This is a platform that offers buyers and sellers from different sectors an online tool to place and sell a product/service. Amazon.com is one successful example of a similar business model;

- Services: E-commerce platforms are not limited to just selling a product. Modern technologies enable users to provide separate online services, such as training, consulting, mentoring, translation, and more (Laudon, 2017).

As already mentioned, this is not a complete list, and new trends and models are evolving daily. Often e-commerce platforms combine several models at once. The e-commerce 
business is the future. Without it, too many companies will not be able to develop soon, and for many, it will be, or already is, the only way to survive.

The main challenge for the implementation of commercial models in the virtual space remains the choice between own and existing e-commerce platforms:

- Creating your website with e-commerce (electronic payment) functionality - to make a payment by bank card, or to receive orders and to find alternative payment methods (for example, sending an invoice and checking the payment yourself);

- Use of existing intermediary e-commerce platforms - well-known Georgian or international platforms such as BOOKING.COM, or even TUREBI.GE.

Both ways have their advantages. It is better to present the brand on your website, there are no restrictions, and if any, even the negative reviews of the user can disappear from the website. Most importantly, there is no intermediary service fee. However, all of this has its downsides: Creating a website is not cheap; Promoting your website is much more expensive and difficult than the globally known platforms, such as amazon.com, in addition to protecting transactions (payments) with additional security issues.

Using existing platforms also has its pros and cons: it is much simpler, it is possible to access millions of people who already use this website (global platform), there are no restrictions on the use of several different platforms, transactions are more secure. The downside can be that even a few customer negative reviews can damage a reputation; Customers have many other similar choices on the same platform; The intermediary website (platform) receives a certain fee for each transaction.

In line with world practice, despite the negative characteristics mentioned above, it is almost irreplaceable for small businesses to do business using existing intermediary platforms. E-companies trying to restructure their marketing management system, promote innovative models, attract highly qualified staff to actively use and create new e-commerce platforms, will be able to increase e-commerce competitiveness (Chenjie Li, 2020).

The functionality that all online trading platforms should have is as follows:

- Several payment methods;

- Multilingual;

- Integration with social pages;

- Compatibility with mobile devices;

- Bank installment;

- Delivery service.

Similar Georgian platforms are Turebi.ge, sastumroebi. ge, hotel24.ge, and others - for placing hotels; SS.GE, Myhome.ge and others - for renting houses, apartments and other real estates; Mymarket.ge, ss.ge buy-sell section, etc. - for the sale of items; Soflidan.ge - agricultural product with online home delivery service; Hotsale.ge and Swoop.ge - discount platforms; Allwine.ge - online wine shop; Agronavti - a mobile application where you can place agro products and offer them to distributors. This list is not exhaustive and is constantly being updated.

\section{CONCLUSIONS AND SUGGESTIONS}

Thus, in conclusion, it may be difficult to give a specific answer to the question of what makes an e-commerce platform and/or product page attractive to users, however, constant thinking in this direction, constant communication with page visitors and buyers, constant experimentation and updated style attempts a condition for reaching the ideal page concept for the product.

As for the prospects, we think it is advisable to pay some attention to the following issues: At present, the country does not have information on the digital economy of Georgia and, consequently, the volume of e-commerce, the turnover of Internet companies, the volume of products, the number of Internet service providers. Also, there is no information on such important statistics as the share of e-business in GDP, the number of people employed in Internet companies, revenues, e-business development indicators. Consequently, it is difficult to make accurate predictions of the development of the e-commerce environment. At the same time, it should be noted that the quality of Internet services is high in Tbilisi, and in the regions - low, which significantly hinders the development of e-commerce.

It should be noted that informational, educational, online tourism, financial services are popular in the Georgian internet market. Internet users are also actively consuming search engines, online games, online applications, e-exchanges, and other services. Consumer behavior and motivation are influenced by the convenience of receiving the service, low price, a wide range of services, short search, and purchase time.

In the world of COVID-19, in a world of uncertain economic forecasts, the long-term prospects of buying and selling online are great, e-commerce entrepreneurs may not be fully protected from health and economic crises, but these crises are still far from over. On digital. We hope that by actively investing in e-commerce, we will create even more opportunities to succeed in the future market. 


\section{REFERENCES:}

ACI Worldwide, (2020). COVID-19 Crisis Drives Changes in eCommerce Purchasing Behaviors, ACl Worldwide Research Reveals, URL: https://investor.aciworldwide.com/node/21496/pdf

Arno Ham, (2020). B2B e-commerce trends in 2021 and beyond,

Chenjie, Li, (2020). E-Commerce Enterprise Marketing Management: Realistic Dilemma, Main Incentives, and Resolution Strategies, Open Journal of Social Sciences Vol.8 No.7, July 23, 2020, DOI: 10.4236/jss.2020.87020

E-Commerce Association of Georgia,

Kanchaveli, G. (2019). E-Commerce - Theory and Practice, Guide, Tbilisi. (In Georgian)

Katie Jones, (2020). The Pandemic Economy: What are Shoppers Buying Online During COVID-19?, URL: https:// www.visualcapitalist.com/shoppers-buying-online-ecommerce-covid-19/

Kenneth C. Laudon, Carol Guercio Traver (2017), E-commerce: business. Technology. Society.

Khan, M., Shams-E-Mofiz, M. and Sharmin, Z. (2020) Development of E-Commerce-Based Online for COVID-19 Pandemic. iBusiness Vol.12 No.4November 26, 2020, 113- 126. DOI: 10.4236/ib.2020.124008. https:// www.scirp.org/pdf/ib_2020112515062913.pdf

Olivia De Beukelaer, (2021). B2B e-commerce and COVID-19: The challenges, solutions, and opportunities (+ examples), URL: https://www.sana-commerce.com/blog/b2b-ecommerce- covid-19-challenges-opportunities/

URL: https://bawar.net/data0/books/5c63140ab1587/pdf/Kenneth_C_Laudon,_Carol_Guerci o_Tra ver_- _E - C o m merce_2017_(2017,_Pearson).pdf

URL: https://www.marketer.ge/georgian-el-commerce-association/ (In Georgian)

URL: https://www.sana-commerce.com/blog/b2b-ecommerce-trends/,

URL: https://www.scirp.org/pdf/jss_2020072210235010.pdf 